This item was submitted to Loughborough's Research Repository by the author.

Items in Figshare are protected by copyright, with all rights reserved, unless otherwise indicated.

\title{
Dynamic thermal models: reliability for domestic building design
}

PLEASE CITE THE PUBLISHED VERSION

http://dx.doi.org/10.1177/014362449101200401

PUBLISHER

(c) SAGE Publications

\section{VERSION}

VoR (Version of Record)

\section{PUBLISHER STATEMENT}

This work is made available according to the conditions of the Creative Commons Attribution-NonCommercialNoDerivatives 4.0 International (CC BY-NC-ND 4.0) licence. Full details of this licence are available at: https://creativecommons.org/licenses/by-nc-nd/4.0/

\section{LICENCE}

CC BY-NC-ND 4.0

\section{REPOSITORY RECORD}

Lomas, Kevin J., D.P. Bloomfield, A. Cole, F. Parand, and A.A. Pinney. 2019. "Dynamic Thermal Models: Reliability for Domestic Building Design". figshare. https://hdl.handle.net/2134/17459. 
Surnmary This paper describes a three year UK iniciative-Applicability Study 1-to enhance the usability and credibility of detailed thermal simulation programs with particular reference to the design of passive solar dwellings. Researchers at Lejcester Polytechnic and the Building Research Establishment are working with ESP, HTB2 and SERIRES. The aims are to identify the problems for which these programs can be used reliably and those for which they cannot, to provide guidance on the best modelling techniques, indicate the uncertainty inherent in predictions, identify the attributes of programs which are necessary to obtain reliable results, and indicate areas in which additional theoretical or experimental research is needed. The results to date show that good agreement in some design trends can be obtaincd provided a high level of quality control is exercised and program users have a good understanding of the theoretical basis of the programs. There were, however, some situations in which the programs still predicted significant differences in the trends in energy consumption as the building design changed.

These may be explained by the different algorithms employed by the detailed thermal simulation programs and errors in them.

\title{
Dynamic thermal models: Reliability for domestic building design
}

\author{
K J Lomasł BSc PhD CEng MInstE, D P Bloomfield BSc, A Cole $\$$ BSc PhD, F Parandł MSc PhD and \\ A A Pinney $\$$ BSc PhD \\ † Leicester Polytechnic, School of the Built Environment, PO Box 143, Lcicester LE1 9BH, UK \\ ‡ Building Research Establishment, Garston, Watford WD2 7JR, UK \\ § Energy Technology Support Unit, AERE, Harwell, Oxon OX11 ORA, UK
}

Received 12 September 1990, in final form 22 April 1991

\section{Introduction}

Detailed thermal simulation programs (DSPS) play a key role in the UK Department of Energy's (DEn) Passive Solar Design Programme (PSP) as, potentially, they provide the most cost-effective way of resolving the key issues encountered in the assessment of building designs. The Energy Technology Support Unit (ETSU), acting on behalf of the

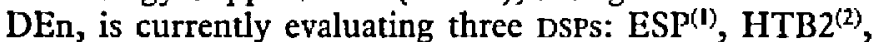
and SERIRES ${ }^{(3)}$

In a recent study, expert users of each of these programs were requested to predict the annual energy use of a passive solar house, the Linford house ${ }^{(4)}$. Widely differing predictions were obtained for the absolute annual auxiliary energy consumption and, more significantly, the trends in energy use as the window area and type were varied (Figure 1). Thermal programs have been shown by others to disagree on the trends in energy use caused by simple design changes ${ }^{(5)}$. The poor results for the Linford house were attributed to a poor building specification, errors in interpreting the specification and in modelling the building (external errors ${ }^{(6)}$ ) and to the inherent differences in the algorithms used by the programs (internal errors $\left.{ }^{(6)}\right)$. Such results seriously undermine the credibility of DSPs since the design solution will depend on the DSP used for the analysis. Clearly, this poses a serious barrier to their application both within the passive solar programme and, more widely, within the building design community.

A seven man-year research initiative, Applicability Study 1 (AS1), is therefore being funded by ETSU. This research is being undertaken by Leicester Polytechnic (LP) with the Building Research Establishment (BRE) acting as the major subcontractor. The aim is to enhance the usability and credibility of DSPS by mapping out their error characteristics. Specific objectives, in order of priority, include:

(a) identifying the design problems for which DSPs can be used with reliability and those for which they cannot; (b) identifying the attributes which a DSP must possess in order to solve a particular design problem;

(c) estimating the inherent uncertainty in the predictions of DSPS and hence the resolution which is possible;

(d) providing guidance on the optimum method of using DSPS;

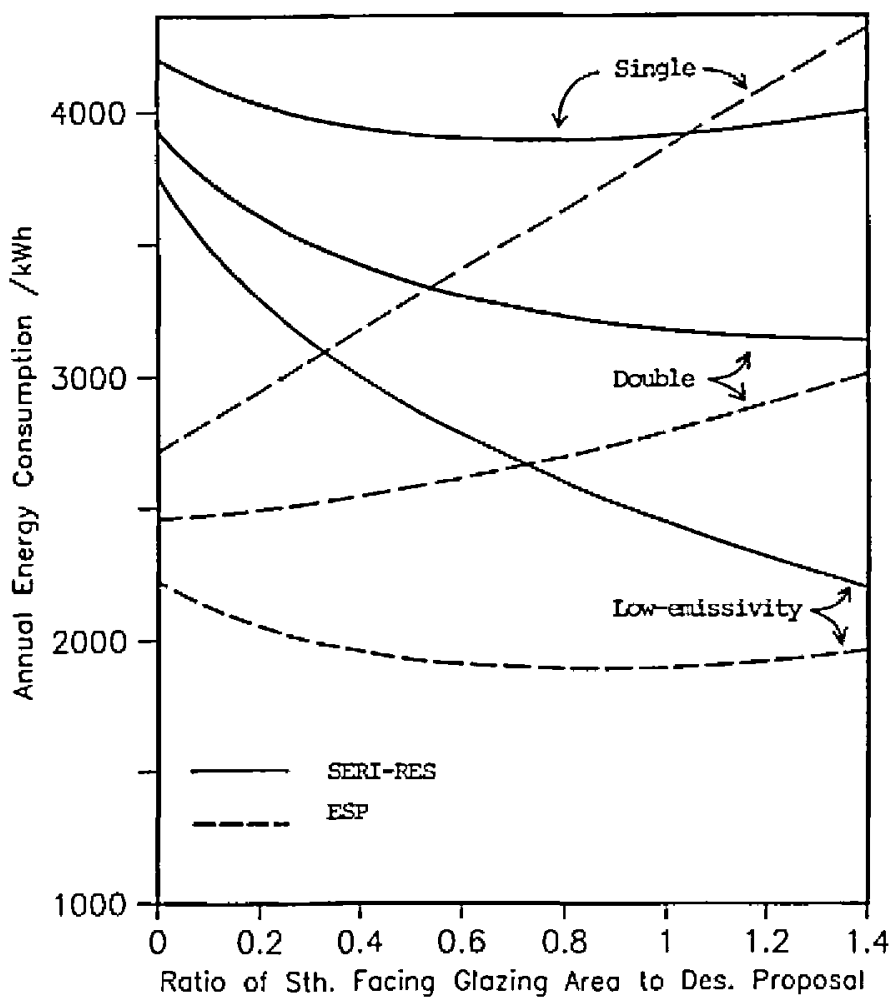

Figure 1 Comparison of annual auxiliary energy consumption predictions made by ESP and SERIRES for the Linford passive solar house 
(e) identifying the need for further theoretical or experimental research; and

$(f)$ identifying the features of DSPs which need further development and validation.

Given the ambitious goals of the project, it was necessary to limit the scope of the study to domestic buildings, and special attention was given to direct-gain passive solar houses. Issues relating to daylighting and detailed plant component modelling were not addressed. The research programme devised to fulfil these objectives has five distinct stages. This paper briefly describes the overall research strategy, the analysis techniques, and some of the principal results.

\section{Selection of model evaluation techniques}

Alternative methods of validating DSPS were evaluated in a recent major Science and Engineering Research Council/ $\mathrm{BRE}$ research initiative ${ }^{(7)}$. It is clear from this work that analytical verification is inappropriate for the AS1 work because such tests can only be applied to individual algorithms within a DSP. Additionally, it is difficult to extrapolate from the results of a few verification tests to obtain information about the performance of the program as a whole ${ }^{(8)}$. Although empirical validation can address whole program performance, it is extremely expensive and time consuming and so only a very small number of simple buildings could be analysed within the timescale of the project ${ }^{(9)}$.

Other techniques: sensitivity analysis, parametric studies and inter-model comparisons, have played a key role in AS1. The techniques can be applied easily and quickly to the complete range of buildings likely to be encountered within the PSP, and it is possible to apply rigorous quality control standards to maintain the integrity of the work. Unfortunately none of these three techniques provides an exact truth model so, while gross internal errors in the programs may be detected, it is not possible to determine the precision of the absolute values predicted. However, if three or more programs predict similar trends, despite their use of different algorithms and solution techniques, the confidence in the ability of DSPS to address the particular problem will have been increased. When the trends predicted by the programs diverge, very specific, and carefully specified, empirical validation (or analytical verification) tests can be undertaken to determine the cause of the divergence. This approach has been used by others and has shown unequivocally the existence of internal errors in DSPS ${ }^{(10)}$. This paper illustrates the benefit of this form of interaction between the different program assessment techniques.

\section{Visualisation of the modelling process}

To rationalise the objectives of $A S 1$, it is useful to visualise a DSP as a 'black box' containing algorithms (Figure 2). Some of these accept inputs, some produce outputs and some only interact with, and pass calculated values to, other algorithms. The exact nature of the algotithms, the frequency with which they are assessed, and the way they interact with each other during a simulation, vary from program to program. (Some programs also provide alternative algorithms for the same thermal process.) Therefore, even if DSPS are provided with exactly compatible inputs and the algorithms contain no coding errors, different values would be expected for the same output parameter.

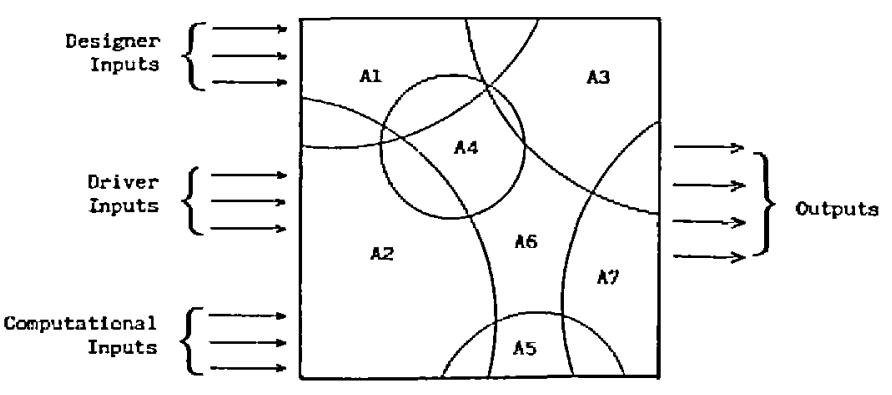

Figure 2 Visualisation of detailed thermal simulation programs

Three types of input have been identified in AS1: designer inputs; driver inputs; and computational inputs. Designer inputs are manipulated consciously by the user to reflect the form of the building under investigation; in this sense they are determinate. There will, however, be some differences between the actual building and that described by the designer inputs, due to approximations made by the program user (e.g. ignoring window reveals), and the chosen inputs will inevitably differ from those prevailing in the field (e.g. thermophysical properties of materials). Thus, although the designer inputs are 'known' there is some uncertainty associated with them.

Driver inputs describe the external and internal conditions to which the finished building will be exposed. These are indeterminate at the design stage so the robustness of a proposed design must be tested by subjecting it to a wide range of plausible weather and occupancy patterns.

The division between designer and driver inputs is not always clear. For example, in a 'tight' building, the winter ventilation rates are largely determined by the designer, and so ventilation rate becomes a designer input. In a building with moveable partitions geometry is at the discretion of the occupants and hence could be classed as a driver input.

Computational inputs are values which have to be given simply because a DSP is being used. They bear no physical relationship to, and have no influence on, the designer and driver inputs. They relate primarily to the conduction algorithms used in the programs (e.g. node placement and time step).

Outputs describe the predicted performance of the building (e.g. internal temperatures and energy use). All DSPs provide a wide choice of possible outputs since the values of importance depend on the problem being studied.

\section{Selection of designer inputs}

A major problem in AS1 was the selection of the building configurations. At one extreme these could represent real, multi-zoned, multi-storey UK dwellings, at the other, very simple hypothetical 'boxes'. Both the whole house ${ }^{(11,12)}$ and the simple hypothetical building approach ${ }^{(13)}$ have been used in previous program validation studies. Complex structures are difficult to model precisely and identically with a range of DSPS, and they require large input files which are difficult to document. This increases the likelihood of input data errors and incompatibility between the inputs supplied to different DSPS. Only a small number of designs could therefore be analysed and it would be difficult to disaggregate individual thermal effects, to generalise the results to other situations, and to compare the results with those of measure- 
Table 1 Menu of designer inputs from which a complete building description is generated

\begin{tabular}{|c|c|c|c|}
\hline Section & Aspect & Variant & Description \\
\hline \multirow[t]{9}{*}{ Geometry } & Type & GT1 & \\
\hline & & GT2 & \\
\hline & Shape & GS1 & 0.57 \\
\hline & & GS2 & $1.0 \mathrm{~d} / \mathrm{w}$ yalues \\
\hline & & GS3 & $1.5\}^{\mathrm{d} / \mathrm{w} \text { values }}$ \\
\hline & & GS4 & 2.0 \\
\hline & Area & GAl & $12 \mathrm{~m}^{2} 7$ \\
\hline & & GA2 & $\left.16 \mathrm{~m}^{2}\right\}$ Area of floor \\
\hline & & GA3 & $20 \mathrm{~m}^{2}$ \\
\hline \multirow[t]{8}{*}{ Constructiont } & Mode & CMIA & Traditional heavyweight \\
\hline & & & $U=1.4 \quad Y=3.8$ \\
\hline & & CMB & Modern heavyweight \\
\hline & & & $U=0.5 \quad Y=2.3$ \\
\hline & & $\mathrm{CMC}$ & Modern lightweight \\
\hline & & & $U=0.5 \quad Y=0.9$ \\
\hline & & CMD & Advanced heavyweight \\
\hline & & & $U=0.3 \quad Y=2.4$ \\
\hline \multirow[t]{10}{*}{ Windowsł } & Area & WA1 & $20 \%$ \\
\hline & & WA2 & $33 \%$ As percentage \\
\hline & & WA3 & $45 \%$ of floor area \\
\hline & & WA4 & $55 \%$ \\
\hline & Type & WT1 & Single glazing, $U=5.6$ \\
\hline & & WT2 & Double glazing, $U=2.9$ \\
\hline & & WT3 & Low-emissivity, $U=1.6$ \\
\hline & Orientation & WO1 & $180^{\circ}$ \\
\hline & (Azimuth) & WO2 & $90^{\circ}$ \\
\hline & & WO3 & $270^{\circ}$ \\
\hline \multirow{5}{*}{$\begin{array}{l}\text { Plant and } \\
\text { controls }\end{array}$} & Combination $\$$ & PCA & $\mathrm{Mix} / \mathrm{mix}$ \\
\hline & & РCB & Mix/convective \\
\hline & & PCC & Air/mix \\
\hline & & PCD & Air/convective \\
\hline & Capacityf & $\begin{array}{l}\text { PC1 } \\
\text { PC2 }\end{array}$ & $\begin{array}{l}\text { Sized } \\
\text { Infinite }\end{array}$ \\
\hline
\end{tabular}

† External wall, internal wall and floor constructions vary with mode. Thermal transmissivity $\left(U, \mathrm{~W} \mathrm{~m}^{-2} \mathrm{~K}^{-1}\right)$ and admittance $\left(Y, \mathrm{~W} \mathrm{~m}^{-2} \mathrm{~K}^{-1}\right)$ quoted for exterior walls only.

$\ddagger$ Details relate to shaded window (see GT1, GT2).

\$ Variants related to control/plant. Mixed plant produces $60 \%$ radiant and $40 \%$ convective heat, convective is $100 \%$ convective. A mixed controller senses $60 \%$ mean radiant temperature and $40 \%$ air temperature, air control senses $100 \%$ air temperature.

fi Sized means plant capacity sized by steady-state method, infinite means plant has unlimited capacity.

ments made in real buildings. Simple buildings help to overcome some of these difficulties and thus many more inter-model comparisons can be undertaken with the same computational effort. Because of these advantages, passive solar design guidance, produced by countries participating in International Energy Agency Task VIII ${ }^{(13)}$, was generated by modelling single-zone structures.
The AS1 work therefore focused on simulating a single zone within a house, the living room, with the intention that additional zones will be added later to study inter-zonal heat transfer phenomena. To conduct the parametric studies, it was essential that individual aspects of the building could be varied independently of each other. Therefore, the designer inputs were divided into four 'Sections', and within each Section, a number of 'Aspects' were defined. By examining 'standard building descriptions' generated for DSPS by others ${ }^{(14-17)}$ it was possible to identify a number of 'Variants' for each Aspect (Table 1).

A full set of designer inputs was produced by combining one Variant from each Aspect. Since each variant had a code any building description could be defined uniquely by a string of such codes (e.g. GT1, GS1, GA2, CMD etc.). The total number of Variant permutations permitted around 18000 living room designs to be investigated. These designs covered the range to be found in the current, and likely future, UK housing stock. They therefore represent newer (passive solar) designs, as well as more traditional buildings. Buildings of the newer type are clearly central to the PSP. The more traditional buildings represent the references against which innovative designs may be compared or which may be subject to refurbishment schemes.

\section{Selection of driver inputs}

Single-day simulations were used for the early AS1 work because the simulation times are very short, permitting numerous inter-program comparisons to be made. It also made it possible to isolate the specific meteorological conditions for which the DSPS produce good agreement from those conditions for which they did not. The AS1 work was conducted using UK design day data generated for ETSU by Loxsom $^{(12)}$. Work has also been undertaken at the Cranfield Institute of Technology, in collaboration with Leicester Polytechnic, to assess the applicability of test reference years and short reference years.

The inputs describing the internal conditions were, as for the designer inputs, devised by reviewing standard building descriptions ${ }^{(14-17)}$. They span the range of conditions likely to be encountered in the living spaces of UK houses (Table 2) and they permit over 250 different combinations of internal and external conditions to be investigated.

\section{Selection of outputs}

Although DSPS are capable of providing very detailed information about building performance, the parameters generated are often either inappropriate to resolve the design issue of interest or, if relevant data are produced, they are embedded among large quantities of output which is irrelevant. Furthermore, the output format depends on the DSP in question.

The principal objective of a passive solar design is to reduce auxiliary energy consumption by maximising the use of adventitious (particularly solar) gains, while maintaining comfortable conditions. Of the many physical and psychological factors which affect our perception of comfort, only two, air and mean radiant temperatures, were generated by the programs ${ }^{(18)}$. These two are frequently averaged to give dry resultant temperature which is in the principal parameter used to specify interior temperatures in the UK. 
Table 2 Menu of driver inputs from which a complete set of internal and external conditions is generated

\begin{tabular}{llll}
\hline Section & Aspect & Variant & Descriptions \\
\hline Weatherf & Type & MT1 & Cold, cloudy winter day, WISZ \\
& & MT2 & Cold, sunny winter day, WICL \\
MIT3 & Typical winter day, WIAV \\
& & MT4 & Cool, sunny spring day, SPCL \\
& & MT5 & Typical spring day, SPAV \\
& & MT6 & Hot, sunny summer day, SMISZ \\
& & MT7 & Typical summer day, SMAV \\
Occupancy & Schedule $\neq$ & OSA & No occupants, no heating \\
& & OSB & No occupants, continuous heating \\
& & OSC & Two occupants, heated 07-09 and 16-23 hrs \\
& & OSD & Four occupants, heated 07-23 hrs \\
Thermostat & Setpoint & TS1 & $21^{\circ} \mathrm{C}$ \\
& & TS2 & $18^{\circ} \mathrm{C}$ \\
& & TS3 & $24^{\circ} \mathrm{C}$ \\
Ventilation & Rate5 & VR1 & $0.35 \mathrm{ach}^{-1}$ \\
& & VR2 & $1.00 \mathrm{ac} \mathrm{h}^{-1}$ \\
& & VR3 & $1.5 / 10.0 \mathrm{ach}^{-1}$ \\
\hline
\end{tabular}

† Single days representing complete range of UK conditions. DSP data files devised by Loxsom, WISZ etc. are the Loxsom code letters.

Hourly profiles of curtain opening and closing and radiative, convective and latent gains defined for OSC and OSD.

5 Fixed air change rates for VR1 and VR2, VR3 rate is 1.5 unless temperature exceeds $25.0^{\circ} \mathrm{C}$ when occupants open windows and rate increases to 10 .

Hourly values of 11 parameters were generated for each simulation (Table 3 ) and from these, 11 daily performance metrics (DPMS) were calculated to succinctly describe the overall daily performance (Table 3 ). These data were produced in an identical succinct format for each DSP, either by customising the output routines, or by post-processing the standard program output. Further analysis and manipulation were then undertaken by non-program-specific software (section 8.3).

\section{The research programme}

\subsection{Stage 1: Basic simulations}

The aim of this stage was to assess rigorously the reliability with which DSPS could predict design trends (for example the variation of energy use with window area) when used by expert modellers. The outputs of the three DSPs were therefore compared (an inter-program comparison) as the designer (and driver) inputs were gradually varied (a parametric study). The objectives were:

(a) to identify the conditions for which the programs predict the same trends, and those for which they do not, and hence to give guidance as to when they can be used to predict design optima and when they cannot.

(b) to quantify the level of agreement between (similar) trends (as represented by the slope of the output versus designer input curve) and hence give guidance on the reliability of predictions, for example, of energy savings.

(c) to gain insight into the causes of divergent trends and hence to clarify the main issues to be examined in Stages 3, 4 and 5 .

A more complete description of the Stage 1 research procedure, and a discussion of some principal results, is the subject of the second part of this paper (section 8 and onwards).

\subsection{Stage 2: Sensitivity analyses}

The sensitivity of the outputs to the inherent uncertainty in the individual designer inputs is currently being quantified. The analysis is being undertaken for a few carefully selected sets of designer and driver inputs. The individual designer

Table 3 Hourly outputs and daily performance metrics

\begin{tabular}{ll}
\hline Hourly & Daily \\
\hline Plant power input & Total heating energy use \\
Zone air temperaturef & Peak power output \\
Glass internal surface temperature & Mean, Max., Min., air temp. $\dagger$ \\
Six opaque surface temperatures & Mean, Max., Min., mean radiant temp. \\
Mean radiant temperature & Mean, Max., Min., dry resultant temp. \\
Dry resultant temperature $\dagger$ & (Time of occurrence of Max., and Min.)
\end{tabular}

† For SERIRES replaced by enclosure temperature. 
input to which the programs are particularly sensitive can thus be identified. It should therefore be possible to give program users guidance on which designer inputs have to be chosen with care and which have little influence on the predictions.

The total uncertainty in the program predictions, due to the inherent uncertainty in all the designer inputs, is also being determined. This will give an estimate of the minimum uncertainty which must be attributed to program predictions and hence an indication of the maximum possible resolution. This minimum uncertainty will provide a benchmark against which to compare the results from Stages 3, 4 and 5 .

A comparison of the attributes of three possible sensitivity analysis techniques, simple differential sensitivity analysis $(D S A)^{(19)}$, stochastic sensitivity analysis (SSA) ${ }^{(20)}$, and Monte Carlo analysis $(\mathrm{MCA})^{(21,22)}$ has been published elsewhere ${ }^{(23)}$. On the basis of conclusions drawn, DSA was selected as the main technique for use in this study.

\subsection{State 3: Computational inputs}

The aim of this stage was to give guidance on the selection of the computational inputs. Emphasis was placed on optimising the node placement and preconditioning strategies in order that computational effort was minimised without compromising the accuracy of predictions.

The studies have now been completed, and methods of reducing both the preconditioning time and the number of nodes have been devised, so that the computer run time can be reduced by a factor of 20 in some cases ${ }^{(24)}$.

\subsection{Stage 4: Modelling assumptions}

When modelling any building, the program user makes, with or without realising it, numerous assumptions; typically window reveals, furnishings, window frames and internal doors are ignored. The influence of such assumptions will be examined by repeating some of the basic simulations with features modelled explicitly that were previously ignored. The aim will be to give guidance on the level of modelling detail which is necessary to achieve optimum predictive accuracy.

\subsection{Stage 5: Algorithmic substitution}

This is probably the most complex stage of the project. It involves substituting the algorithms employed in a program with alternative ones, and repeating some of the basic simulations to assess the effect. From Stage 1, guidance should be forthcoming about which algorithms are crucial, and which design problems are particularly sensitive to the choice of algorithms.

In Stage 5, guidance on the algorithms which a DSP must employ in order to resolve specific design issues will be produced. Thus, it will be possible to: appraise the adequacy of the current algorithms; recommend modifications to DSPS; and to identify the need for new algorithms, or further fundamental research, of either a theoretical or experimental nature.

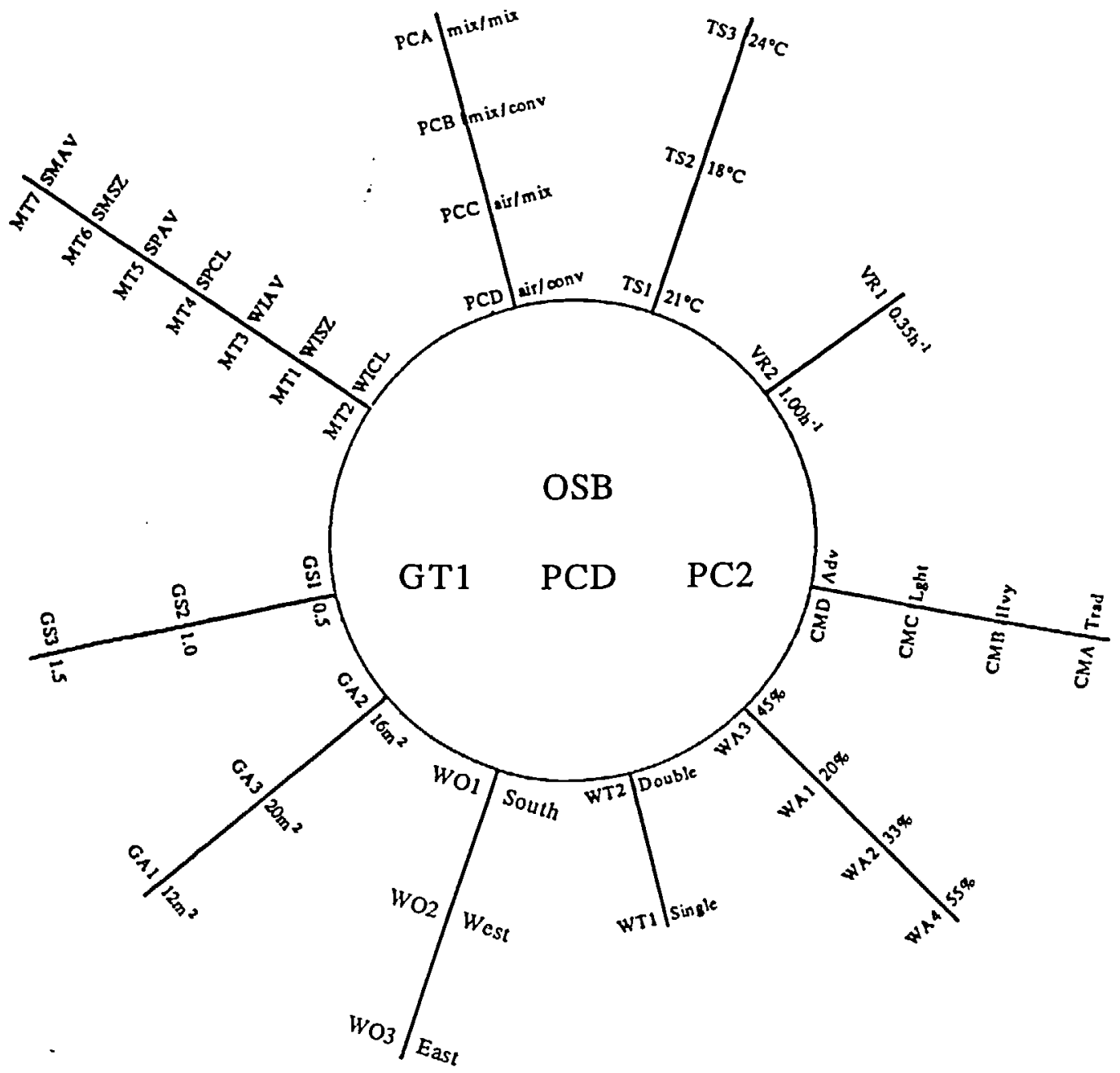

Figure 3 Representation of the simulations conducted in Round 2B (For definitions of code letters see Tables 1 and 2 . Section 8.1 gives further explanation.) 


\section{Stage 1 research}

The remainder of this paper concentrates on the research procedures and the results obtained from Stage 1 . However, the interaction with work to be done in the other stages is illustrated.

\subsection{Experimental procedure}

The primary objective of Stage 1 was to identify the conditions under which the programs give similar predictions of design trends (and absolute values) and the conditions under which they do not. So a research method based on making single parameter excursions was adopted.

A particular set of designer and driver inputs was selected for the first 'base case' simulation (represented by the code letters in, and immediately surrounding, the hub of the 'wheel' in Figure 3). Then, a particular Aspect (e.g. window area) was selected, and a number of simulations were undertaken using different Variants of this Aspect (e.g. changing the window area from $45 \%$ (WA3) to $20 \%$ (WA1), $33 \%$ (WA2), then 55\% (WA4) of floor area). All other input values were held constant at their base-case values, so only the one Aspect was varied at a time. Single-parameter excursions of this type were made for each Aspect of interest (represented by the spokes of the wheel in Figure 3) until a complete 'Round' of simulations was complete. The results from five such rounds are discussed in this paper. Each Round was undertaken for each program and the outputs (Table 3) compared, in particular, the DPMis (e.g. daily energy use) as each Aspect (e.g. window area) was varied. This method produced direct information about the similarity, or otherwise, of the trends predicted by the programs. Thus, it was possible to test the widely held belief that, although programs predict different absolute values, they predict the same trends.

For each Aspect studied, the predicted trends (e.g. of daily energy use versus window area) were classified as Similar, Almost Similar, Different or Flat (Table 4) and, when the trends were Similar, the level of agreement between the predicted gradients was classified as either Excellent, Good, Poor or Bad (Table 5). The classifications relevant to this paper relate to energy use predictions; similar criteria have been devised to evaluate the trends in the other DPMS of interest (e.g. peak power and temperatures). The level of agreement in the absolute predicted values has also been classified in a similar way. These classifications were devised by considering the accuracy which is desirable from the programs in order to resolve real design problems. Once Stage 2 has been completed, it should be possible to replace

Table 4 Classification of predicted trends

\begin{tabular}{ll}
\hline Classification & Definition \\
\hline Similar & $\begin{array}{l}\text { All programs produce the same trend for the energy } \\
\text { usage of each Variant (of the Aspect studied). }\end{array}$ \\
$\sim$ & $\begin{array}{l}\text { All programs identify the same Variants as the highest } \\
\text { and lowest energy consumers but one model ranks the } \\
\text { intermediate Variants in a different order. }\end{array}$ \\
Different & $\begin{array}{l}\text { Programs differ in their prediction of the highest and } \\
\text { lowest energy consuming Variants. }\end{array}$ \\
Flat & $\begin{array}{l}\text { All programs predict less than 5\% difference between } \\
\text { the energy use of the highest and lowest consumers. }\end{array}$
\end{tabular}

Table 5 Classifying the level of agreement when trends Similar

\begin{tabular}{ll}
\hline Classification & Definition \\
\hline Excellent & $\begin{array}{l}\text { Predicted overall energy savingst differ by less than } 5 \% . \\
\text { Good }\end{array}$ \\
& $\begin{array}{l}\text { Predicted overall energy savings differ by between } 5 \text { and } \\
10 \% .\end{array}$ \\
Poor & $\begin{array}{l}\text { Predicted overall energy savings differ by between } 10 \\
\text { and } 15 \% .\end{array}$ \\
Bad & Predicted overall energy savings differ by over $15 \%$. \\
\hline
\end{tabular}

$\dagger$ The difference between the energy consumed by the lowest and highest energy consuming Variants (of the Aspect studied) as a percentage of the highest energy consumption.

these desired accuracies with criteria based on the actual resolution possible from the programs.

The research method produces direct information about the ability of the programs to predict the performance of individual zones within domestic UK buildings. However, by analysing the results carefully it should be possible to begin to make inferences about the applicability of these and other DSPS for addressing problems which lie outside this immediate area of interest. In particular, for predicting the annual performance of whole domestic buildings and the performance of individual spaces in some non-domestic buildings.

\subsection{Preliminary studies}

On the basis of the results of previous work ${ }^{(19)}$, three nodes were placed in each layer of material in all three programs, and a time step length of 15 minutes was used for ESP. HTB2 and SERIRES, which use an explicit finite-difference solution technique, used a much shorter (18 to 90 second) time-step, to maintain computational stability. Preliminary Stage 3 work indicated that results were sensitive to the choice of initial node temperature and preconditioning time and that, without an exhaustive study, 19 days preconditioning should be used to obtain reliable results. Each simulation (after Round 2B) therefore consisted of 20 identical days with the output produced only for the final day. The adequacy of these assumptions has been confirmed by the recently completed Stage 3 work ${ }^{(24)}$.

Modelling assumptions will be studied in detail in Stage 4; however, for the purposes of conducting the Stage 1 simulations, it was assumed that there were no site or facade features to cause shadows and that there were no internal doors or furnishings in the room. Because only the performance of the living room was of interest, the thermal effect of the adjacent zones was modelled in an approximate way by introducing a fictitious layer of material at the remote side of the internal walls such that the total resistance and admittance of the structure was maintained.

The programs were used without any modifications to the algorithms and (in Stage 1) in the mode which a typical user would adopt (i.e. using the default algorithms). However, difficulties were encountered in aligning the timing conventions used in the three programs. Studies indicated that, for UK weather data, there is a shift of half an hour between the times at which SERIRES demands inputs (for weather data and casual gains) and at which it produces outputs, and the corresponding times used by HTB2 and ESP. Thus, hourly results for SERIRES are plotted on the hour while 


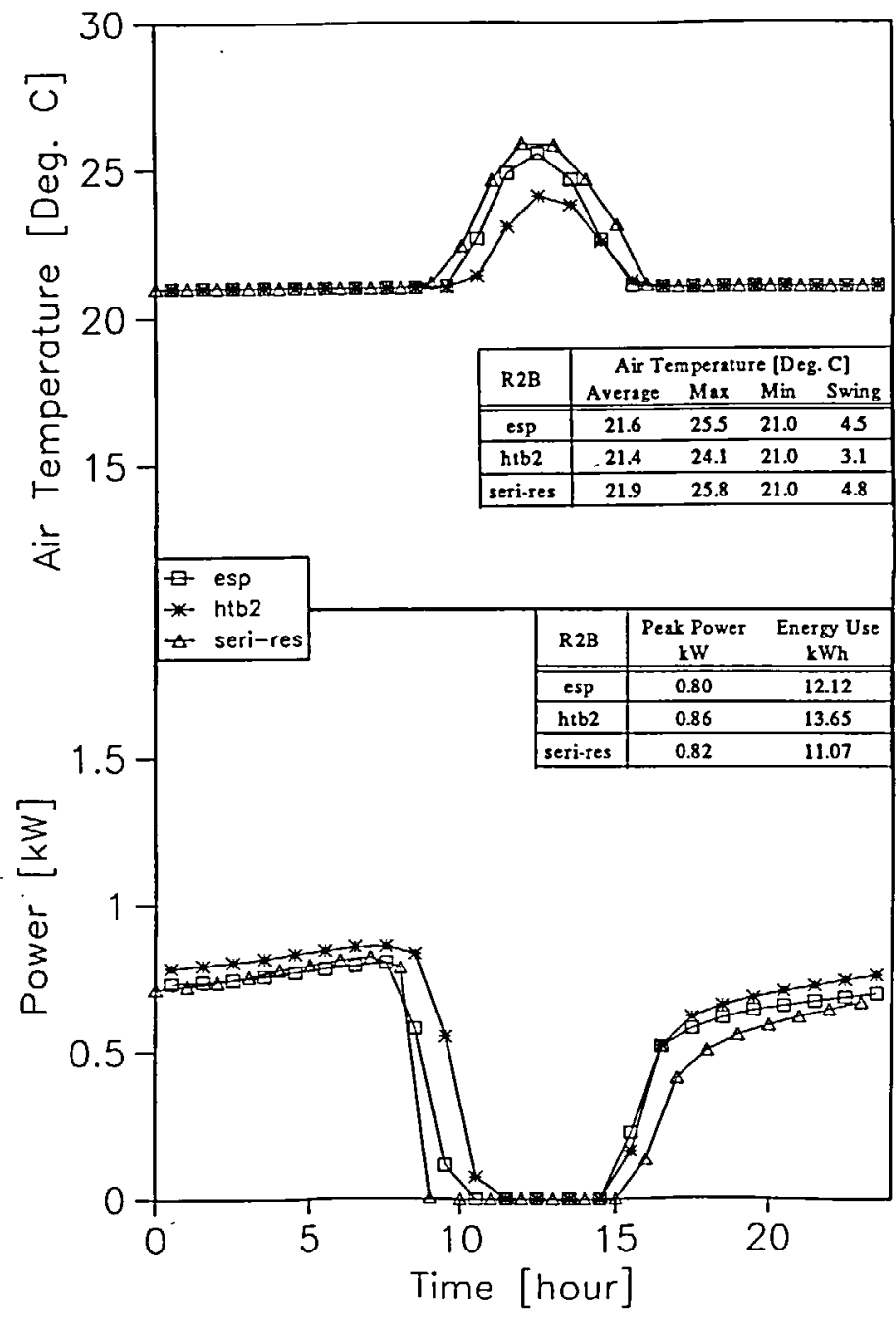

Figure 4 Hourly results and daily performance metrics for the Round $2 \mathrm{~B}$ base case building

those for ESP and HTB2 are plotted on the half hour (e.g. Figure 4). Difficulties were also encountered when trying to model the floor and the underlying earth, since none of the programs have explicit algorithms for dealing with this issue. It is beyond the scope of this paper to explain the nature of these problems and the solutions obtained; however a realistic approach was devised which could be implemented identically in all three programs and which did not impose any computational penalties. Ground modelling algorithms are currently being investigated in a separate project at Leicester Polytechnic.

\subsection{Minimising experimental error}

For a given design problem, different inputs will be needed and different outputs will be produced, depending on the DSP to be used. Furthermore, the formats of these inputs and outputs will vary. It was therefore difficult to create exactly compatible input files even for the AS1 buildings, which were relatively simple. To minimise the scope for human error, rigorous quality control procedures were adopted. Central to these procedures was the completion of a data 'input proforma' for the base-case buildings. In the proforma, values were given for every single input parameter required by each program and the pages were designed so that the inputs required by the different DSPs, for the same building feature, appeared side-by-side. Omissions, dis- crepancies or incompatibilities in input data were therefore immediately obvious.

Each researcher transferred the relevant values manually from the proforma to one program and checked the input files. These were then also checked by the other two researchers in the team. The process of undertaking a basecase simulation, the modification of the input files to conduct the other simulations in the Round, and the comparison and plotting of the outputs were fully automated to avoid human error and the need for further laborious manual checks.

All the program input files, the output files and the graphs were stored both on computer tape and as hard copy. This permitted any erroneous simulations to be repeated and it provides an archive for future program evaluation work.

\subsection{Rounds completed}

By selecting the base-case building carefully, and the excursions to be undertaken, it is possible, in theory, to probe the complete multi-dimensional parameter space represented by all the Designer and Driver inputs. In practice, time prevents such a complete analysis so the abilities of the DSPS have to be inferred from a more limited set of tests.

To date, six Rounds, representing over 120 simulations with each program have been completed; in five of these the building was heated. Because of the interest in modern passive solar buildings, particularly the Linford House for which the divergent simulation results were originally obtained (Figure 1), the living room of the Linford house was adopted as the base-case building for four of the Rounds. In Round 2B, double glazed, and Round 5, single glazed, the room was heated continuously whereas in Round 6, single glazed, and Round 7, low-emissivity glazing, the room was intermittently occupied and heated for two periods each day. The base-case room for Round 4 had traditional construction and single glazing and was therefore more typical of a building which could be subjected to passive solar refurbishment. In all the base cases, cold sunny winter weather was chosen since this enabled the accuracy with which DSPS predict interactions between solar gain and heating system performance to be tested. It is also under these climatic conditions that the full benefits of passive solar design can be realised. Table 6 gives a full list of the Variants used in each base case building and in Table 7 their principal differences are described.

\subsection{Programs used}

Rounds $2 \mathrm{~B}, 4$ and 5 were undertaken using ESP version $6.8 \mathrm{a}$ and HTB2 version 1.0. Following these Rounds, modifications to HTB2, made by Leicester Polytechnic, were completed to enable the thermal effects of blinds and curtains to be modelled. Errors in ESP, which were discovered as a result of the work (see sections 10.3 and 10.4) were eventually traced and corrected by the program authors. Thus,

Table 6 Base case inputs for Rounds 2B, 4, 5, 6 and 7

\begin{tabular}{|c|c|c|c|c|}
\hline Round & Designer input & & Driver input & \\
\hline $\mathrm{R} 2 \mathrm{~B}$ & CMD WA3 WT2 & & TS1 VR2 OSB? & \\
\hline R4 & CMA WA4 WT1 & GT1 GS1 & TS2 VR1 OSB & \\
\hline R5 & CND WA3 WT1\} & $\mathrm{GA} 2 \mathrm{WO1}$ & TS1 VR2 OSB & MT2 \\
\hline R6 & CMD WA3 WT1 & PCD PC2 & TS1 VR2 OSC & \\
\hline R7 & CMD WA3 WT3] & & TS1 VR2 OSC J & \\
\hline
\end{tabular}


Table 7 Brief overview of the base case buildings

\begin{tabular}{|c|c|c|c|c|c|c|}
\hline \multirow[t]{2}{*}{ Round } & \multicolumn{3}{|c|}{ Designer inputs } & \multicolumn{3}{|c|}{ Driver inputs } \\
\hline & $\begin{array}{l}\text { Construction } \\
\text { mode }\end{array}$ & $\begin{array}{l}\text { Window } \\
\text { area (\%) }\end{array}$ & $\begin{array}{l}\text { Window } \\
\text { type }\end{array}$ & $\begin{array}{l}\text { Thermostat } \\
\text { set-point } \\
\left({ }^{\circ} \mathrm{C}\right)\end{array}$ & $\begin{array}{l}\text { Ventilation } \\
\text { rate }\left(\mathrm{ac} \mathrm{h}^{-1}\right)\end{array}$ & $\begin{array}{l}\text { Occupancy } \\
\text { schedule }\end{array}$ \\
\hline R2B & Advanced heavyweight & 45 & Double & 21 & 1 & None/Continuous \\
\hline R4 & Traditional heavyweight & 55 & Single & 18 & 0.35 & None/Continuous \\
\hline R5 & Advanced heavyweight & 45 & Single & 21 & 1 & None/Continuous \\
\hline R6 & Advanced heavyweight & 45 & Single & 21 & 1 & Two/Two Period \\
\hline R7 & Advanced heavyweight & 45 & Low-E & 21 & 1 & Two/Two Period \\
\hline
\end{tabular}

Rounds 6 and 7 were undertaken with the enhanced version of HTB2, and ESP version 6.18a. SERIRES version 1.2 was used for all the Rounds. All three programs were mounted on SUN 3/60 work stations linked to various peripherals.

\section{Hourly results}

In all three Rounds in which the building was continuously heated (2B, 4 and 5) the solar and casual gains were sufficient to maintain the specified set point during the daytime without any contribution from the heating system. The air and dry resultant temperatures were similar and the mid-day

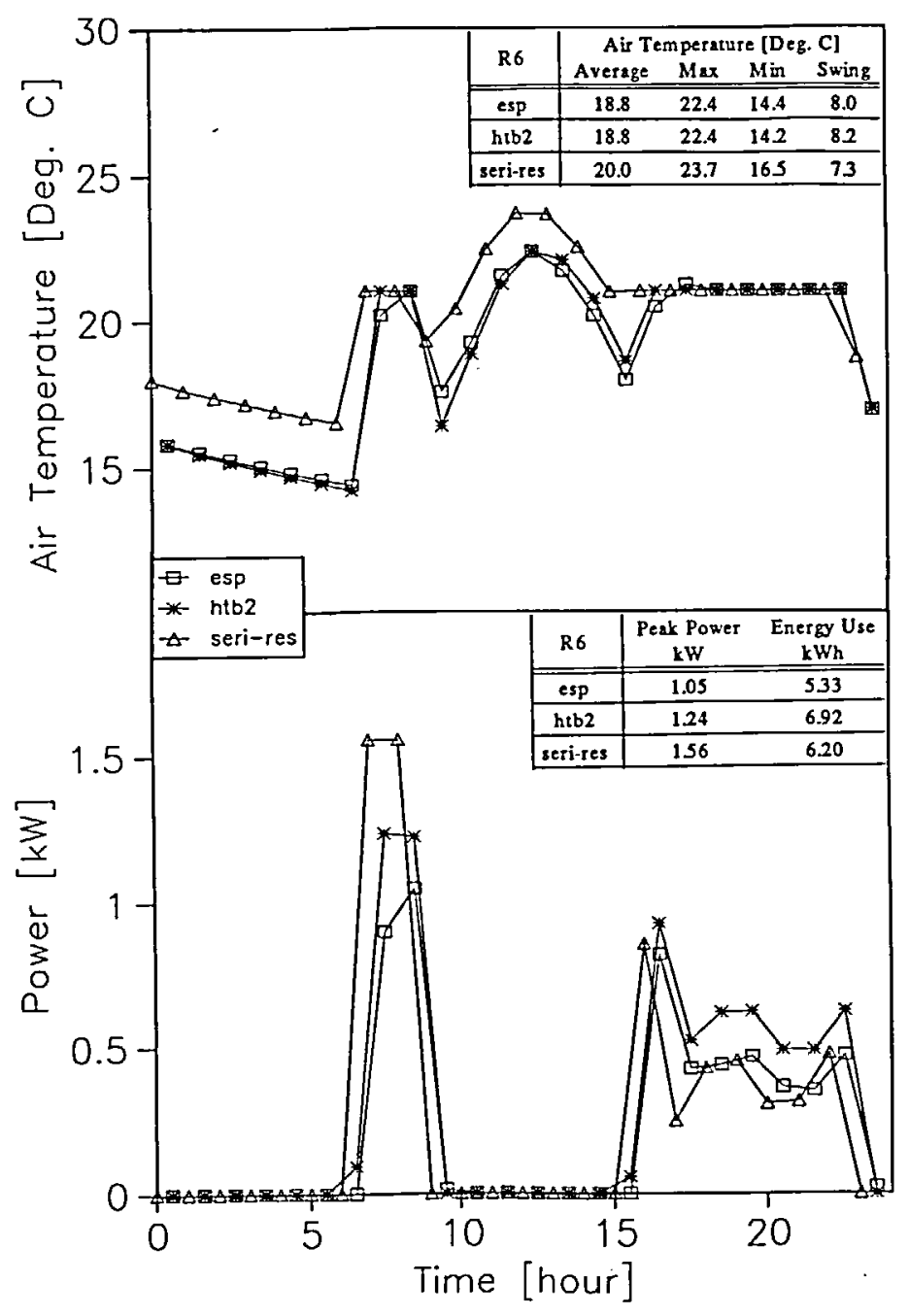

Figure 5 Hourly results and daily performance metrics for the Round 6 base case building temperatures were not uncomfortably high (e.g. Figure 4). Similarly, in the Rounds where the building was intermittently heated ( 6 and 7) the mid-day temperatures were only marginally above the set point (e.g. Figure 5).

Although the three programs predict similar hourly trends (without any obvious phase shifts), there are significant differences in the DPMS (shown on Figures 4 and 5), particularly for peak power demand at start-up and daily energy use. The remainder of this paper focusses on the prediction of the trends in daily energy use, which is the issue of paramount importance in passive solar design. The prediction of air temperature, mean radiant temperature, and, most importantly, dry-resultant temperature will be reported elsewhere.

\section{Comparison of predicted trends in energy use}

\subsection{Driver inputs}

The internal and external conditions to which a building will be exposed, as embodied by the driver inputs, cannot be predicted in advance by the program user. However, there are occasional situations in which the thermostat set point and ventilation rate may, to a large extent, be defined by either the designer or building manager rather than the building occupants (e.g. in sheltered housing for the elderly). In any case, by studying the ability of the program to predict trends in these parameters, and the trends as the meteorological conditions change, insight into the performance of the program can be gained.

In Rounds $2 \mathrm{~B}$ and 4, the influence of ventilation rate was assessed, and the programs predicted the same trends and were in Excellent or Good agreement in their prediction of the reduction in energy use as a result of decreasing the ventilation rate from 1 to 0.35 air changes per hour. Predicted savings were between 19 and $21 \%$ for Round 4 and between 25 and $31 \%$ for Round $2 \mathrm{~B}$. The increased savings thus occur, as expected, in the better insulated building. In these two Rounds, Excellent or Good agreement was also obtained in the prediction of the energy savings as a result of reducing the thermostat set point from 24 to $18^{\circ} \mathrm{C}$ (Figure 6). Absolute energy savings for the poorly insulated building (Round 4) were about double those predicted for the well insulated building (Round $2 \mathrm{~B}$ ) although as a percentage, the energy savings in the latter building were greater (around $50 \%$ in Round $2 \mathrm{~B}$ compared with $40 \%$ in Round 4 ). In Round 7, the programs were in Bad agreement (Figure 6) with predicted savings ranging from $54 \%$ (in HTB2) to $74 \%$ (in SERIRES).

The programs predicted similar trends in energy use as the meteorological data changed. However, they begin to show 


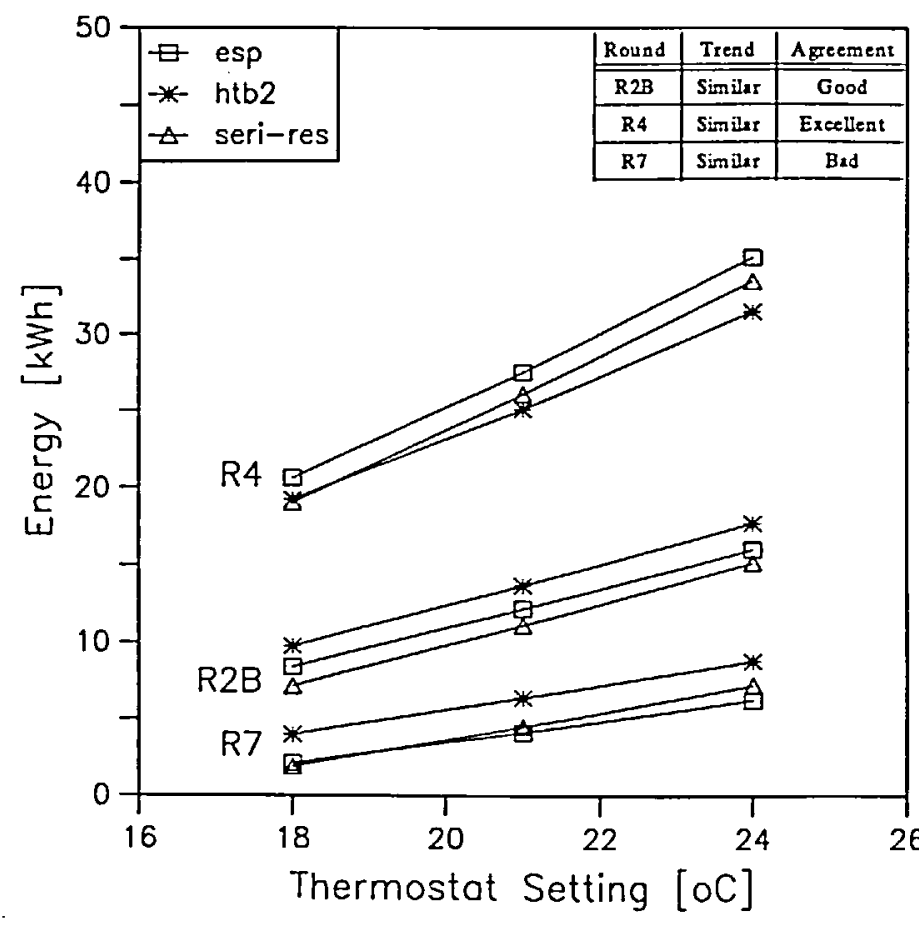

Figure 6 Predicted influence of thermostat set point on daily energy use showing trends for Rounds 2B, 4 and 7

divergence in the absolute values predicted, particularly for the poorly insulated building used in Round 4 and for the colder, cloudier days (e.g. Figure 7). As a result, the relative changes in energy use from one day to the next may differ from program to program. There is a clear need, therefore, to assess the ability of the DSPs to predict annual performance. (The relative differences between the daily predictions of the programs may compound to give very divergent results or, alternatively, they may average out, resulting in annual predictions which agree very closely.)

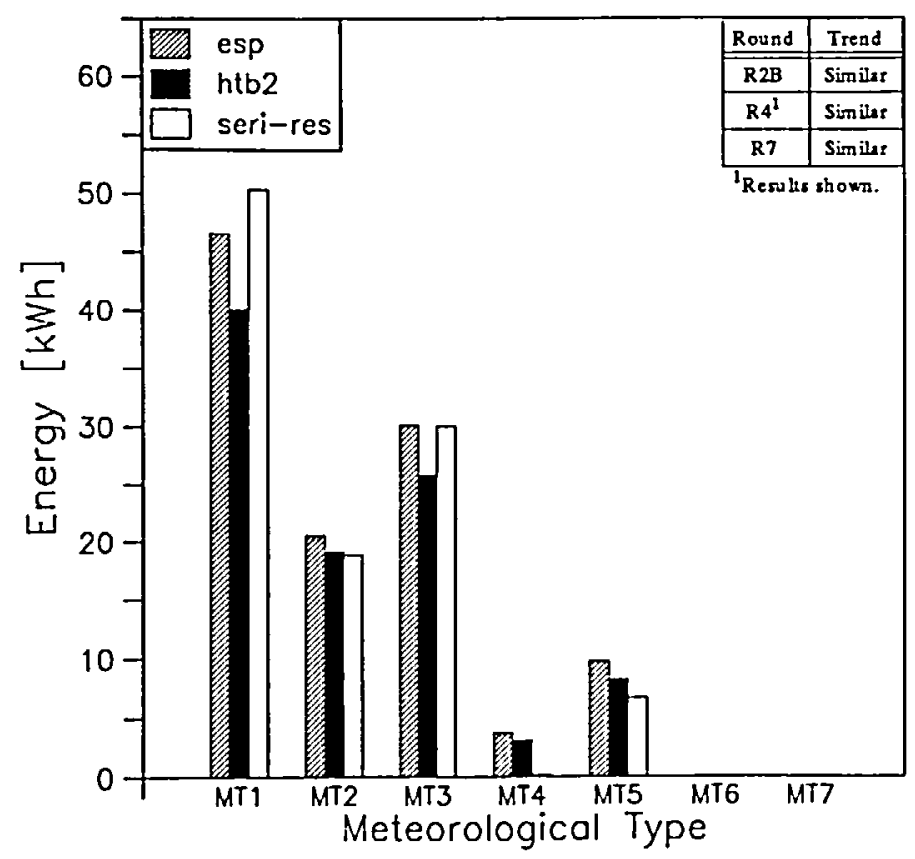

Figure 7 Predicted influence of meteorological type on daily energy use showing results for Round 4
Researchers at Cranfield Institute of Technology have addressed this topic using the AS1 Round 2B building descriptions and a wide variety of Test Reference Years and Short Reference Years for Kew in London ${ }^{(25)}$. There is scope for further work in this area.

The foregoing results indicate that, for a given building and meteorological conditions, the three programs will predict the same trend in energy consumption as the ventilation rate and thermostat set point vary. Thus design optima, related to these Aspects, are unlikely to be influenced by the DSP used for the analysis. Energy savings estimates could, however, differ by as much as $20 \%$ under some circumstances.

\subsection{Geometry and construction}

The programs were in Excellent agreement in their prediction of the energy savings resulting from changes to the building's floor area (GA) and shape (GS). They also showed Similar, or Almost Similar, trends as the construction mode varied (Figure 8). Except for the Round 7 building, the overall predicted energy savings due to changing from a traditional heavyweight construction (CMA) to an advanced heavyweight construction (CMD) were in either Good or Excellent agreement. In all five Rounds, the energy used by construction CMD was around $50 \%$ of that used by CMA. The heavyweight (CMB) and lightweight (CMC) modern constructions, which were insulated to the same level, produced very similar energy use predictions. However, it is worth noting that the diurnal air temperature swings in the lightweight buildings were double those for the heavier construction. This suggests that thermal mass can improve thermal comfort in highly glazed UK houses, without inducing higher heating energy consumption.

These results indicate that, if reducing energy consumption is the aim, the same decisions as to the optimum geometric and constructional form would be reached irrespective of the DSP chosen for the analysis. However, estimated energy savings could differ by as much as $15 \%$.

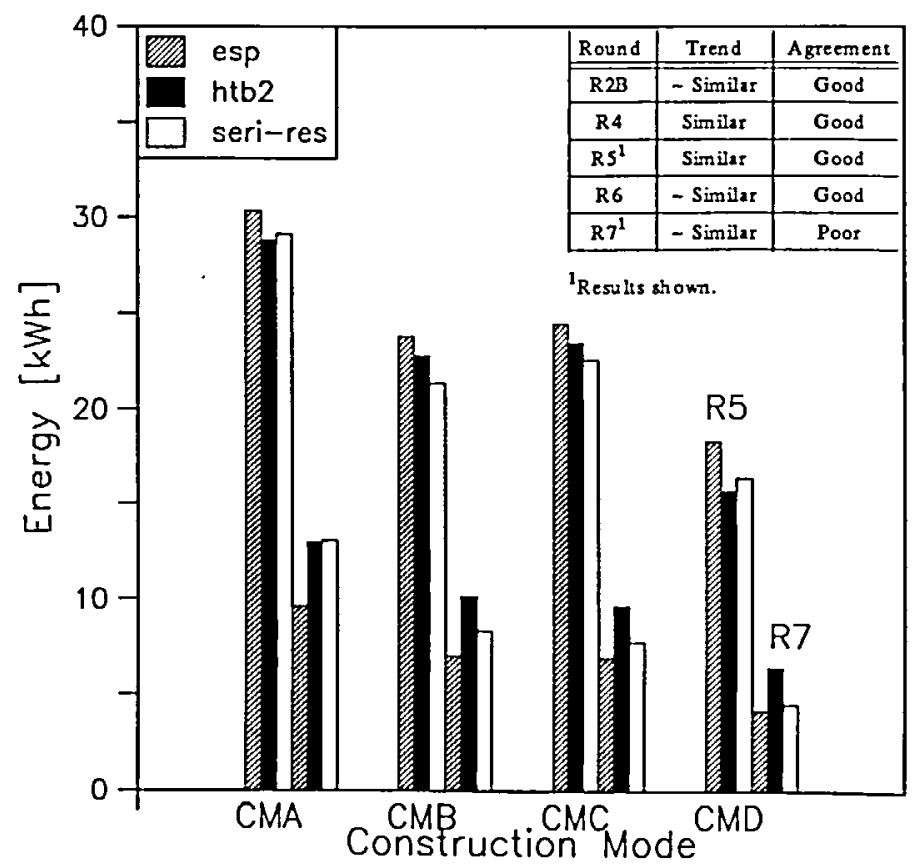

Figure 8 Predicted influence of construction mode on daily energy use showing results for Rounds 5 and 7 


\subsection{Window area}

Reliable predictions of the variation of energy use with window area are crucial for passive solar design. Unfortunately, it is just such predictions for which poor results were originally obtained (Figure 1). Compared with these results the trends produced in AS1 were in much closer agreement, as were the absolute predicted values (Figure 9). Although only a single zone, rather than a complete house, was simulated, this greatly improved agreement is attributed primarily to the rigorous quality control procedures which were adopted. It would appear, therefore, that most of the discrepancies in the original Linford house results can be attributed to poor problem specification, to errors in data interpretation, or to program user errors. One valuable product of the ASI work is guidance on quality control and modelling procedures necessary to obtain reliable predictions.

Despite this overall improvement, there are still some obvious differences between the three sets of results, particularly for the buildings which consume the most energy (Rounds 4 and 5). The Round 4 results are particularly discouraging as the trends are completely different. In this instance, a designer would be led to completely different conclusions depending on the program used for the analysis. ESP predicts that the smaller the window area the less energy is used, HTB2 predicts that the larger the window area the less energy is used, and SERIRES predicts minimum consumption with a window area equal to $33 \%$ of the floor area. In Round 5, HTB2 indicated a minimum energy consumption with a glazed area equal to $45 \%$ of the floor area, whereas ESP and SERIRES show decreasing consumption as the window area decreased.

In Rounds 2B, 6 and 7 the predicted trends were Similar and, interestingly, all show decreasing consumption with increasing window area (even for single glazing-Round 6). However, the reliability of the energy savings predictions

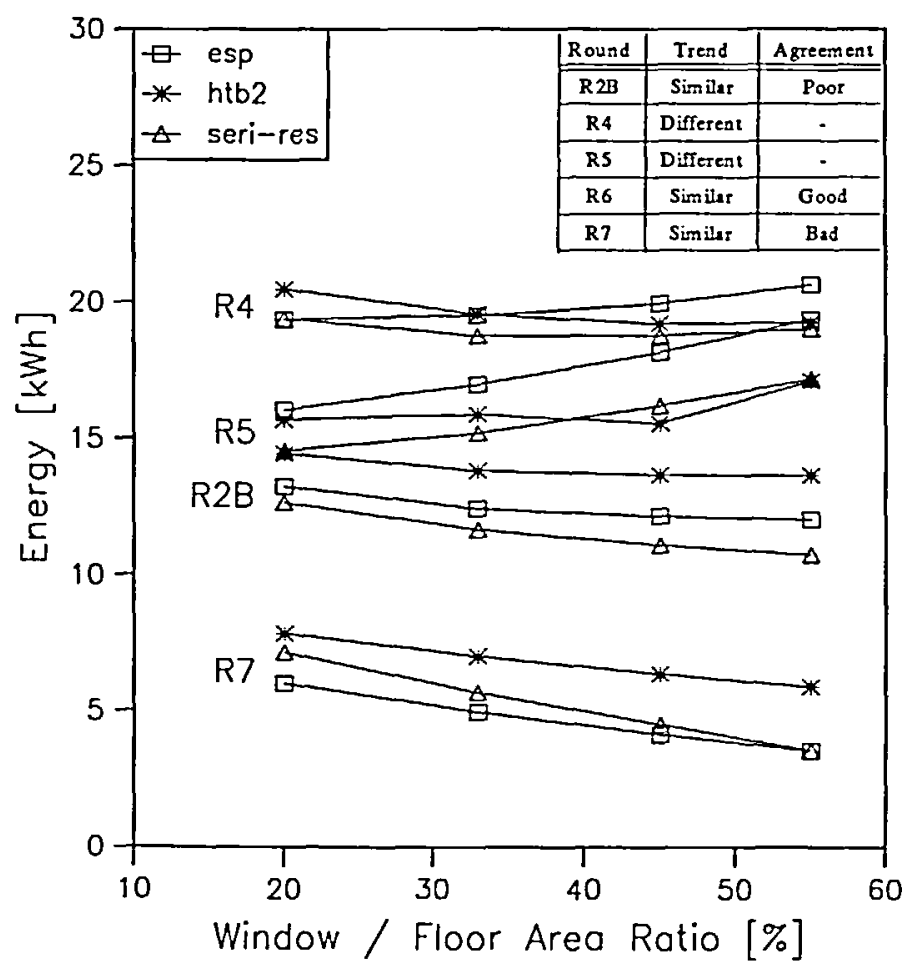

Figure 9 Predicted influence of window area on daily energy use showing results for Rounds $2 \mathrm{~B}, 4,5$ and 7 was erratic. In Round $2 \mathrm{~B}$ predicted savings were from $5 \%$ (HTB2) to $15 \%$ (SERIRES), in Round 6 the variation was from $16 \%$ (HTB2) to $24 \%$ (SERIRES), but in Round 7 the variation was even greater 26\%: (HTB2) to $51 \%$ for SERIRES. In all cases, HTB2 predicts the lowest energy savings and SERIRES the highest. Discrepancies such as these could have a major impact on estimates of the cost effectiveness of alternative glazing strategies.

\subsection{Window type}

The ability of the programs to predict energy savings as the type of window is changed is also of crucial importance in energy-conscious design. Although single glazing is less likely to figure in the heated areas of modern buildings, such systems may be used in conservatories, or in reference designs against which 'energy-conscious' buildings are compared.

In all the Rounds, the three programs were consistent in their prediction of the trends in energy consumption as the window type changed. In Rounds 4 and 5, where the building was continuously heated, the programs ranked the glazing types in the order: single glazing (the highest consumer); double glazing; and then low-emissivity glazing (the lowest energy consumer) (Figure 10). However, in the intermittently heated building (Round 6), all the programs ranked double glazing as better than low-emissivity glazing (Figure 10). The lower solar transmission of low-emissivity glass reduced the solar gain, and hence reduced the size of the mid-day air temperature rise, resulting in the structure retaining less energy for the evening heating period, when the blinds are drawn (see also Figure 5). The information which a designer would be given, as to the optimum window type to use would not, on the basis of these results, be influenced by the program used for the analysis.

The reliability of energy savings predictions is illustrated by comparing the percentage savings due to changing single glazing (WA1) to double glazing (WA2) and then double glazing to low-emissivity glass, WA3 (Figures 11 and 12). HTB2 always predicted the lowest energy savings when going from single to double glazing with ESP and SERIRES

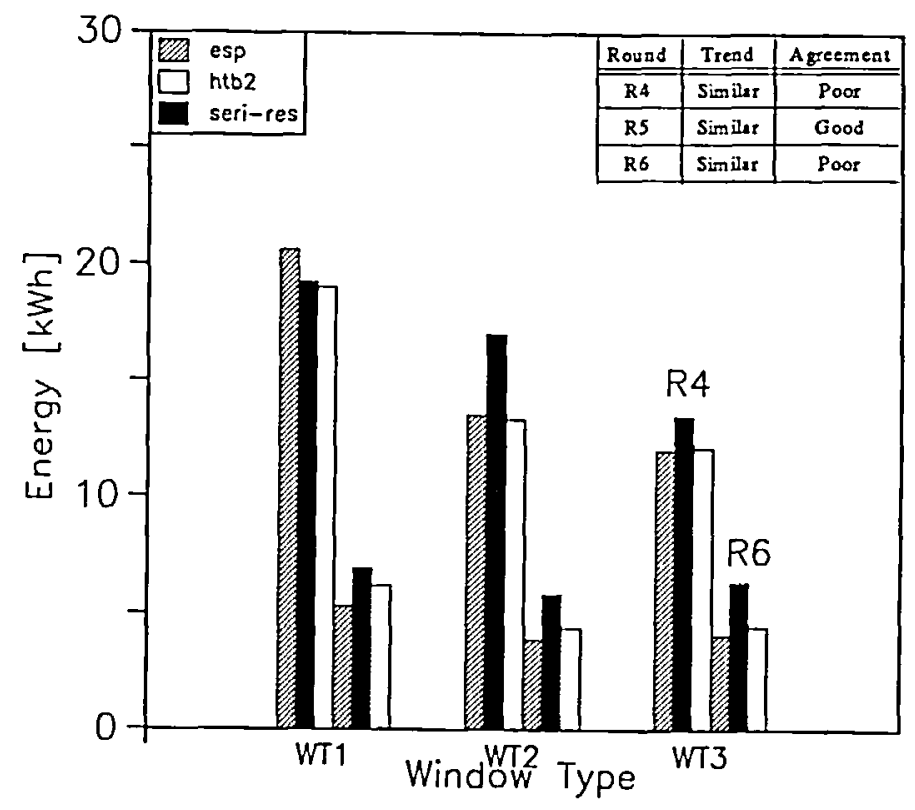

Figure 10 Predicted influence of window type on daily energy use showing results for Rounds 4 and 6 


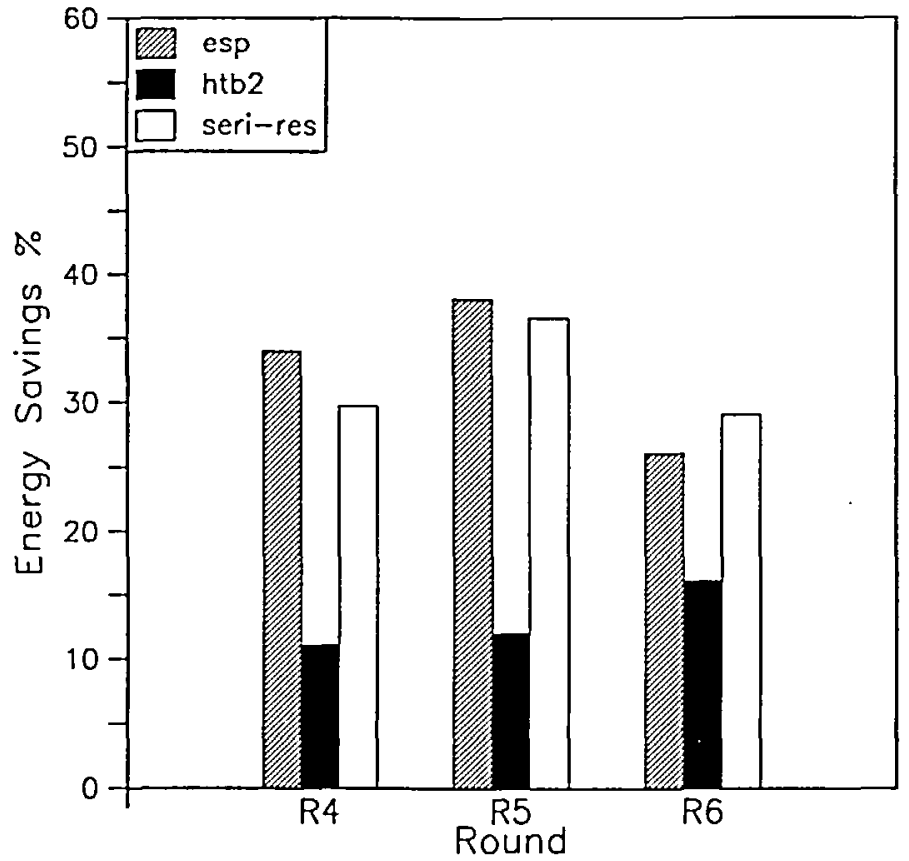

Figure 11 Predicted daily energy savings due to replacing single glazing with double glazing

predicting similar, but greater, savings. (It is worth noting that the variations between the predictions of the programs for a given Round were much greater (sometimes twice as great) as the variation in savings between the Rounds.) For changes from double glazing to low-emissivity glazing no one program consistently predicted either the highest or lowest energy savings (Figure 12), however the variations between the programs were still very large (from $12 \%$ to $32 \%$, in Round 5, for example). The energy savings predictions, and thus estimates of the cost effectiveness of any glazing retrofit, are therefore strongly dependent on the program chosen for the analysis.

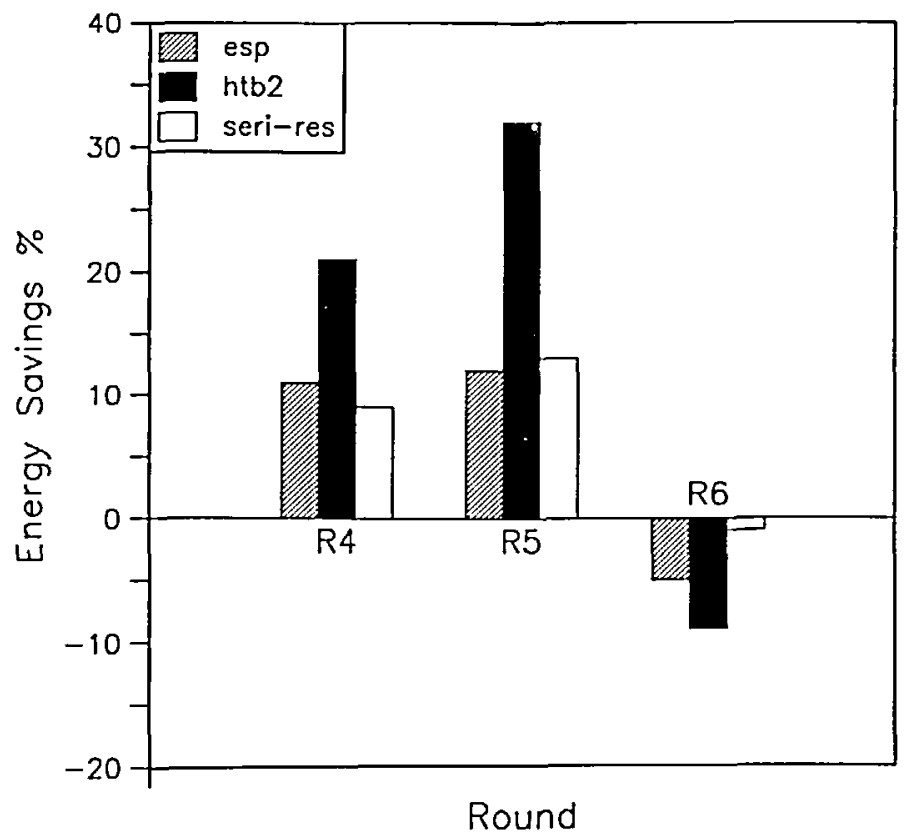

Figure 12 Predicted daily energy savings due to replacing double glazing with low-emissivity glazing

\subsection{Window orientation}

Thermal programs may be called on to optimise building orientation, or to assess the energy use penalties of having large areas of glazing facing away from south (as may be demanded by site layout, shading or amenity considerations). The reliability of DSPS in predicting the variation of energy use with orientation is therefore of great interest.

In all the Rounds, the three programs produced similar trends-minimum energy use when the only window in the building faced south and maximum consumption when the window faced west. In Rounds $2 B$ and 4, where the building was continuously heated, SERIRES and HTB2 predicted that east-facing glazing resulted in the energy use being between $2 \%$ and $9 \%$, less than that for west-facing glass (the exact savings depended on the particular Round and program being used). ESP, however, predicted a reduced energy usage of between $13 \%$ and $26 \%$ for east-facing glazing as compared with west-facing glazing (Figure 13). The differences between the ESP results and those of the other programs were greatest when the window was single glazed (Rounds 4 and 5) and appeared to be a consequence of the differences between the window conduction algorithms which the programs employ. In ESP the window $U$-value varied with wind speed and direction, but SERIRES uses fixed $U$-values. HTB2 models windows as transparent multilayer constructions, and varies the external surface convection coefficient, depending on wind speed and direction.

To test whether the window conduction algorithms could indeed be causing the divergent results, Rounds 6 and 7 were undertaken using an alternative window algorithm in ESP which simply fixes the $U$-value. As a result, the predicted trends for Rounds 6 and 7 agreed much more closely (Figure 13). All three programs predicted minimum energy consumption for south-facing glazing, with west-facing glazing using between $2 \%$ and $9 \%$ more energy (depending on the program) than east-facing glazing. However, the overall energy savings to be made by orientating the glazing south rather than west were variable. For example, in Round

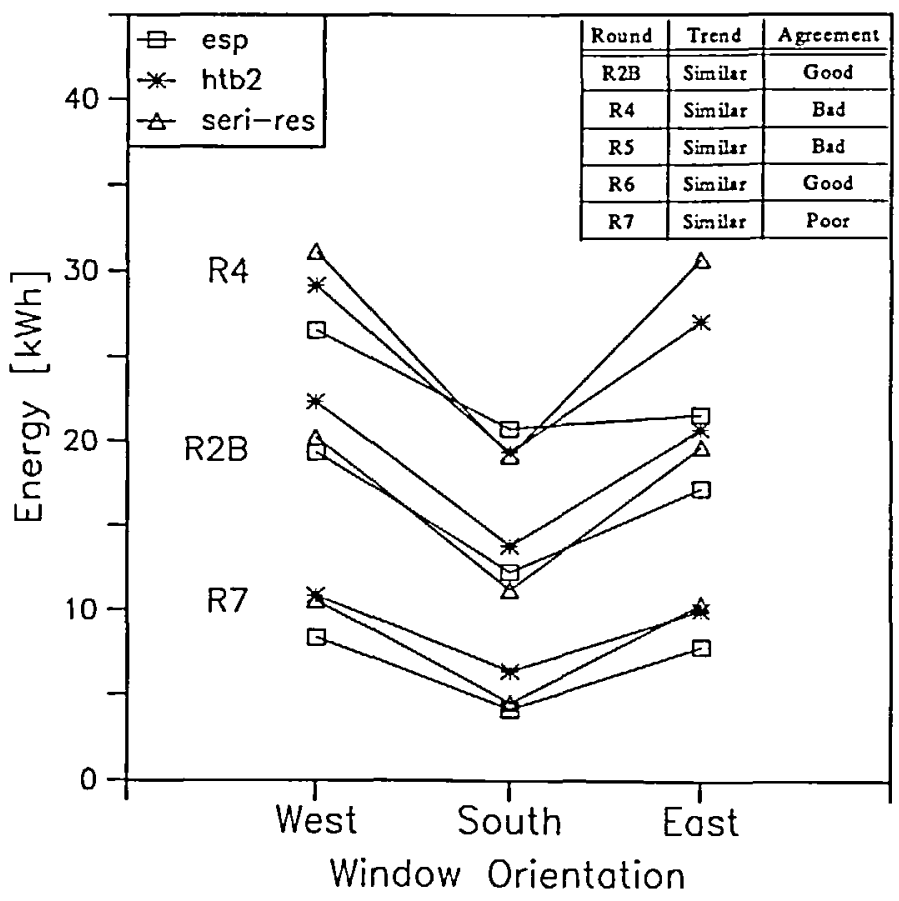

Figure 13 Predicted influence of window orientation on daily energy use showing results for Rounds $2 \mathrm{~B}, 4$ and 7 


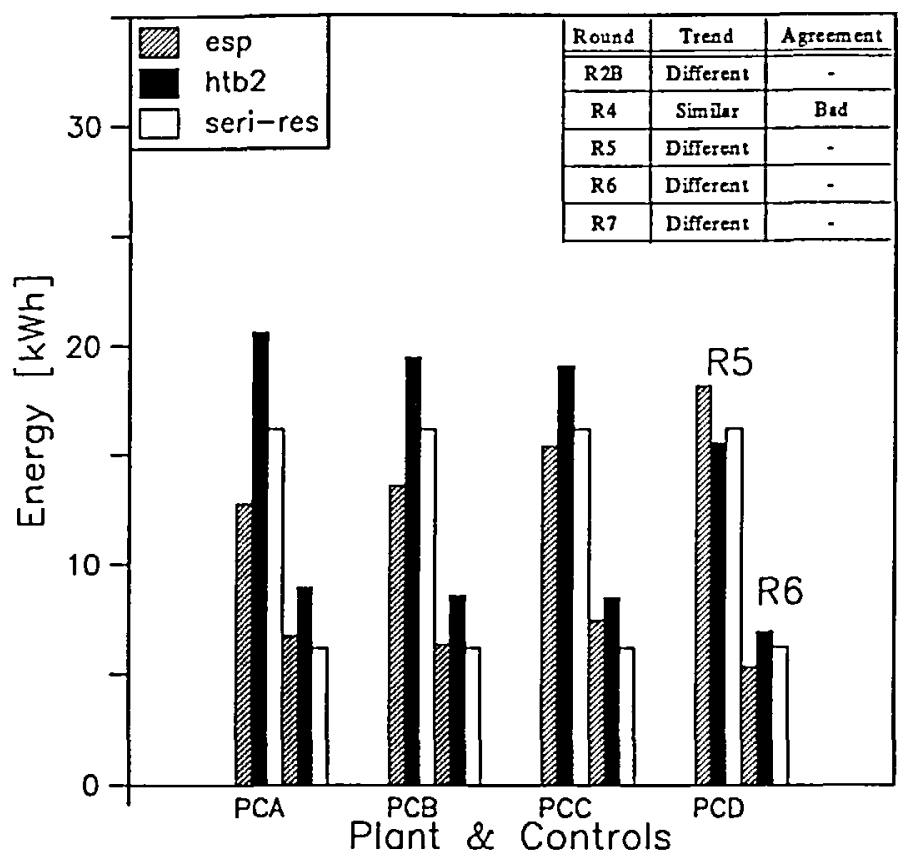

Figure 14 Predicted influence of plant/controls strategy on daily energy use showing results for Rounds 5 and 6

7, SERIRES predicted a $58 \%$ saving whereas HTB2 only predicted a $41 \%$ saving. This is Poor agreement (despite using similar conduction algorithms in all three programs). Clearly, the window conduction algorithm used by the programs can have a significant impact on the building performance predictions which are obtained. They will be the subject of closer investigation in stage 5 of the work.

\subsection{Plant and controls strategy}

Modern domestic buildings in the UK are usually heated by systems based on low-pressure hot water radiators which output a mixture of about $33 \%$ radiant and $67 \%$ convective heat. The other commonly used system, based on warm air, produces almost $100 \%$ convective heat energy. Other systems produce a convective heat output proportion which is between these two extremes. Thermostats also vary in the proportion of mean radiant and convective temperature which they sense. The two extremes can be represented as units sensing a mixture of $33 \%$ mean radiant temperature and $67 \%$ air temperature and one sensing pure (100\%) air temperature. The ability of the programs to predict the performance of the four extreme combinations of heater and thermostat type was investigated (Table 1). Because SERIRES cannot distinguish between radiant and convective heat, it predicts the same values irrespective of the plant/controls system which is employed, so in the analysis of the trends the SERIRES predictions were ignored. Even so, ESP and HTB2 predicted opposite trends for Rounds $2 \mathrm{~B}$ and Round 5. ESP predicted a gradual increase in energy consumption as variants $\mathrm{PCA}, \mathrm{PCB}, \mathrm{PCC}$ and $\mathrm{PCD}$ were used, whereas HTB2 showed a gradually decreasing trend (Figure 14). A completely different design decision would therefore be reached depending on which program was used. In Round 4 , although the trends were Similar, the level of agreement was Bad. It is worth noting that the SERIRES predictions tended to be closest to those of ESP and HTB2 when these programs are modelling a thermostat sensing pure air temperature and a heating system supplying purely convective heat $(\mathrm{PCD})$.
The divergent trends were investigated. This included a consideration of the preliminary results of field trials conducted by the Energy Monitoring Company on behalf of ETSU $^{(26)}$. These suggested that it was the ESP results which were in error, and so the handling of heating and controls systems in ESP was reviewed by the program authors. Programming errors were discovered and modifications made which resulted in version $6.18 \mathrm{a}$ being adopted for Rounds 6 and 7.

The Round 5 excursion for Plant/Control strategy was then repeated with this new version. The absolute energy use predictions of the two programs were in much closer agreement although the trends still differed. This difference in the trends was also observed in Round 6 (Figure 14) and Round 7. Despite modifications to ESP, the selection of heating and controls systems to reduce energy consumption would appear, on the basis of these results, to be influenced by the DSP used for the analysis. This issue is currently being investigated more closely.

\section{Discussion of results and future work}

The results from all the Rounds are summarised in Table 8. The inter-program variations were obtained by considering all the results obtained for each particular Aspect. They are the range of values, in the column headed 'Agreement', in each of Figures 6-14. It is reassuring that for most Aspects, the optimum design (i.e. the variant which consumed least energy) was not dependent on the program used for the analysis. Notable exceptions occur when trying to optimise the heating and controls system and the area of south-facing single glazing.

The reasons for the divergent predictions are being investigated as part of the Stage 5 work. The early signs are that the modelling of internal heat transfer coefficients can have a major impact on the absolute energy use and peak power predictions, particularly for intermittently heated buildings. However, internal heat transfer coefficients do not appear to influence design trends. It may be that the divergent trends for single-glazed window area may be explained by the different window conduction algorithms used by the programs. These algorithmic differences may also explain the high inter-program variations for thermostat set point, window orientation, window type, window orientation and construction mode (Table 8). By studying the window conduction algorithms in detail, undertaking algorithmic substitutions, and making use of experimental data, it is hoped that the most suitable algorithm(s) to use in DSPs can be identified, and hence both the divergent trends and the large inter-program variations can be avoided.

Although this paper has concentrated on energy consumption, air temperature, peak power and internal comfort conditions will also be the subject of detailed analyses in future work. It is likely that this will lead on, in Stage 5, to an assessment of the solar transmission algorithms and the sky models used in the programs since these, in conjunction with the algorithms mentioned above, could have a major impact on the peak (summertime) temperature predictions ${ }^{(27)}$.

Some results from Stages 2 and 4 have been reported ${ }^{(23,24)}$ and considerable progress has been made on Stage 5 . It is evident, because the AS1 buildings studied here are only single zones, that there is an element of risk associated with extrapolating the results to annual simulations for whole 
Table 8 Summary of all the results from the five Rounds

\begin{tabular}{lll}
\hline Aspect of design studied & $\begin{array}{l}\text { Does the predicted } \\
\text { optimum design depend } \\
\text { on the program being } \\
\text { used? }\end{array}$ & $\begin{array}{l}\text { Inter-program variation } \\
\text { in overall energy } \\
\text { savings predictions }\end{array}$ \\
\hline Floor area & No & Under $5 \%$ \\
Room shape & No & Under $5 \%$ \\
Construction mode & No & 5 to $15 \%$ \\
Window area & Sometimest & Up to $25 \% \neq$ \\
Window type & No & 5 to $15 \%$ \\
Window orientation & No\$ & 5 to $15 \% 5$ \\
Plant/controls strategy & Yes fi & - \\
Thermostat set-point & No & Up to $20 \%$ \\
Ventilation rate & No & Under $10 \%$ \\
\hline
\end{tabular}

† For single glazing optimum depends on model used, but not for double and lowemissivity glazing.

¥ Variation for double and low-emissivity glazing.

$\$$ Provided default ESP algorithm not used.

If Even after errors in ESP corrected.

buildings. Some whole-building annual simulations have therefore been undertaken to demonstrate the validity of the advice given for this situation. This work will be reported elsewhere.

In a wider context, the analysis methods adopted for AS1 have succeeded in demonstrating clearly the existence of errors in large DSPS and areas in which their operation is suspect. AS1 has also allowed for a structured interaction between the various validation techniques and capitalised on their relative advantages. This approach has merit for evaluating the predictions of building programs (with different levels of sophistication). The identification of errors and weaknesses in DSPS, despite previous validation work, indicates that there is a continuing need for work of this type. In particular, comparatively little attention has been given to assessing the reliability of DSPs for predicting the performance of non-domestic buildings.

\section{Conclusions}

The research method of Applicability Study 1 has successfully demonstrated how to capitalise on the strengths of the five major program validation techniques, inter-program comparison, parametric studies, sensitivity analyses, empirical validation and analytical verification. The method centres around the use of inter-program comparisons and parametric studies to identify the situations for which program predictions diverge and then uses empirical validation, analytical verification, sensitivity analyses, and an exploration of the theoretical basis of the programs, to explore the reasons for the divergence.

The research method has been applied to domestic-scale UK buildings and has proved capable of identifying when ESP, HTB2 and SERIRES produce the same trends in energy use as an Aspect of the building's design is changed and when they do not. Thus, it has been possible to identify when DSPS seem to produce reliable predictions of design optima, and estimates of energy savings, and when they do not.

By instigating a rigorous quality control scheme, in order to ensure compatible input data for the three programs, the level of agreement between the trends in the energy use predictions of the programs was greatly improved over those obtained in earlier studies. One valuable product of the work will be guidance on the quality control and modelling necessary to obtain consistent predictions.

The three programs agreed to within $5 \%$ in their predictions of the changes in the overall energy use due to alterations in geometry, and to within $10 \%$ for changes to ventilation rate. Because this high level of agreement was obtained, despite using three very different DSPs, the confidence which can be placed in the predictions of energy use changes, for these Aspects of the building, has been greatly increased.

The three programs predicted similar trends for the variation of energy use as either the method of construction or the thermostat set point was altered. There were, however, marked differences between the programs in their prediction of the overall energy savings. The differences were up to $20 \%$ for changes in the thermostat set point and glazing type, and up to $15 \%$ for changes in the construction of opaque surfaces. Therefore, the cost effectiveness of changes to these Aspects, either in an existing building or in a proposed new building, could be influenced strongly by the DSP used for the analysis.

ESP produced different results for the influence of orientation on energy use. This appeared to be a consequence of the differences between the window conduction algorithms employed by the programs. When the default ESP algorithm, which produces a variable $U$-value, was replaced by an alternative, using a fixed $U$-value, the three programs predicted similar trends. However, the energy savings predictions still differed by up to $15 \%$.

For some single glazed buildings, the three programs showed marked disagreement in their predictions of the trends in energy use as the area of south-facing window was varied. Thus, predictions of the optimum area of glazing could depend strongly on the DSP being used for the analysis. Even for situations in which the programs predicted similar trends, their prediction of the overall energy savings to be made by optimising the window area differed by up to $25 \%$. Thus in a retrofit scheme, for example, the cost effectiveness of altering the area of south-facing glazing could depend strongly on the DSP used for the analysis.

SERIRES cannot simulate the influence of either different radiant/convective splits on the heating system output or 
different proportions of air and mean radiant temperature sensed by the thermostat. Although ESP and HTB2 can, they produced markedly different trends for the energy use as the heating plant and thermostatic control type were varied. Despite the correction of a coding error in the plant simulation algorithm in ESP, these large discrepancies remained. So, the programs cannot be relied on to optimise the type of plant (e.g. low-pressure hot water radiator, or warm-air heating system) or the thermostat which is installed.

The divergent trends for window area and plant and controls could be due to the way the programs model window conduction, internal heat transfer coefficients and plant/control interactions. These algorithmic differences may also explain the large inter-program variations in the energy savings predictions, and so they will be examined closely within AS1. To assist in this investigation, test cell experiments have been undertaken to collect field data on the variation of energy use with plant/control type, window area and window type.

The results obtained so far indicated a continuing need for program validation work. In particular, the AS1 research methods could be extended to assess the reliability of DSPS for resolving more complex design problems at both the domestic scale (e.g. conservatory design) and, more importantly, in non-domestic buildings (e.g. integrated lighting and thermal design). This could include an analysis of annual energy use predictions for whole buildings.

\section{Acknowledgements}

This work has been sponsored by the Department of Energy through its Energy Technology Support Unit and is published by permission of the chief executive of the Building Research Establishment.

\section{References}

1 Clark J A and McLean D ESP A building and plant energy simulation system Version 6, release 8 (Glasgow: Energy Simulation Research Unit, Univ. of Strathclyde and ABACUS Simulations Limited) (1988)

2 Lewis $\mathrm{P} T$ and Alexander $\mathrm{D} \mathrm{K} \quad H T B 2-A$ model for the thermal environmental of buildings in operation User Manual Release 1 Rev. 0 154-pp, Technical Reference Manual Release 1 Rev. O (Two volumes) Vol. 1 (1985)

3 Palmiter $\mathrm{L}$ and Wheeling $\mathrm{T}$ Solar Energy Research Institute residential energy simulator Version 1.0 (Golden, CO: Solar Energy Research Institute) (1983)

4 Everett $\mathrm{R}$ et al. Performance of passive solar houses at Great Linford, Milton Keynes Final Report to the Energy Technology Support Unit, Contract No: E/SA/CON/1025/174/020 (Milton Keynes: Open University) (1985)

5 Bloomfield D P The influence of the user on the results obtained from thermal simulation programs Proc. 5th Int. Symp. the Use of Computers for Environmental Engineering Related to Buildings, Bath, UK pp 161-180 (1986)

6 Bowman N T and Lomas K J Empirical validation of dynamic thermal computer models of buildings Building Sero. Eng. Res. Technol. 6(4) pp 153-162 (1985)

7 Bloomfield D P An investigation into analytical and empirical validation techniques for dynamic thermal models of buildings Executive Summary; Vol. 1 (Garston, Watford: Building Research Establishment) (1988)
8 Bland B H and Bloomfield D P Validation of conduction algorithms in dynamic thermal models Proc. Sth Int. Symp. Use of Computers for Environmental Engineering Related to Buildings, Bath, UK, pp 22-35 (1986)

9 Lomas K J Dynamic thermal simulation models of buildings: New method for validation Building Serv. Eng. Res. Technol. 12(1) pp 2537 (1991)

10 Judkoff $\mathrm{R}$ et al. A comparative study of four passive building energy simulations: DOE2.1, BLAST, SUNCAT2.4, DEROB III, Proc. Sth Nat. Passive Solar Conf., Amherst, MS, USA pp 126-130 (1980)

11 Judkoff $\mathrm{R}$, Wortman $\mathrm{D} \mathrm{N}$ and Burch J Empirical validation using data from the SERI Class A validation house Proc. Ann. Meet. American Solar Energy Society, Minneapolis, MN, USA pp 705-710 (1983)

12 Loxsom F Meteorological data for the passive solar programme Collection of reports for the Energy Technology Support Unit, Model Refinement Study (Polytechnic of Central London Research in Building Unit) (1985-86)

13 Holtz $M J$ and Wortman DN A summary of building energy analysis and design tool evaluation results from IEA Task VIII Proc. Building Simulation '89, Vancouver, BC, Canada pp 232-239 (1989)

14 Turrent D and Steemers K Domestic Low Energy, 4 Beyond the Regs Architect's f. 191(15) 61-67 (11 April 1990)

15 Private Communications (Garston: Building Research Establishment) $(1983,1985)$

16 Allen E J and Pinney A A Standard dwellings for modelling: Details of dimensions, construction and occupancy schedules Building Environmental Performance Analysis Club Technical Note TN90/2 (Garston, Watford: Building Research Establishment) (1990)

17 Bloomfield D P The use of thermal models for the production of design guidelines Proc. Int. Climatic Arch. Conf, Louvain-la-Neuve, Belgium (1986)

18 Baillie A P, Griffiths I and Huber J W Thermal comfort assessment, a new approach to comfort criteria in buildings Final Report to Energy Technology Support Unit (Guildford: EICRG, Dept. of Psychology, University of Surrey) (1987)

19 Bowman N T and Lomas K J Developing and testing tools for empirical validation Ch. 14 Vol. IV of SERC/BRE final report on $A n$ investigation into analytical and empirical validation techniques for dynamic thermal models of buildings (Garston, Watford: Building Research Establishment) (1987)

20 Irving A I Hypothesis testing, risks and decisions $\mathrm{Ch} .18 \mathrm{Vol} . \mathrm{V}$ of SERC/BRE final report on $A n$ investigation into analytical and empirical validation techniques for dynamic thermal models of buildings pp 176-287 (Garston, Watford: Building Research Establishment) (1988)

21 Anand D K, Kennish W J, Knasel T M and Stolarz A C Validation methodology for solar heating and cooling systems Energy 4 549-560 (1979)

22 Hunn B D, Turk W V and Wray W O Validation of passive solar analysis/design tools using Class A performance evaluation data Proc. 7th Nat. Passive Solar Conf., Knoxville, PN, USA pp 177-182 (1982)

23 Lomas $\mathrm{K} J$ and Eppel $\mathrm{H}$ Developing and proving sensitivity analysis techniques for thermal models of buildings Proc. Building Environmental Performance (BEP '91), Canterbury, UK pp 253-280 (1991)

24 Pinney A A and Parand F The effect of computational parameters on the accuracy of results from detailed simulation programs Proc. Building Environmental Performance (BEP '91), Canterbury, UK pp 207-219 (1991)

25 Waide P A and Norton B Applicability of short reference years for passive solar building simulation Proc. 2nd European Conf. Architecture, Paris, France pp 27-29 (1989)

26 Martin C J and Watson E M J An investigation of the influence of heater type and thermostat response on passive solar building performance: Modell data comparison study Energy Monitoring Company report to Energy Technology Support Unit No. 1197-E (1988)

27 Allen J P Solar Processes Ch. 8 Vol. II Part 2 of SERC/BRE final report on $A n$ investigation into analytical and empirical validation techniques for dynamic thermal models of buildings (Garston, Watford: Building Research Establishment) (1987) 